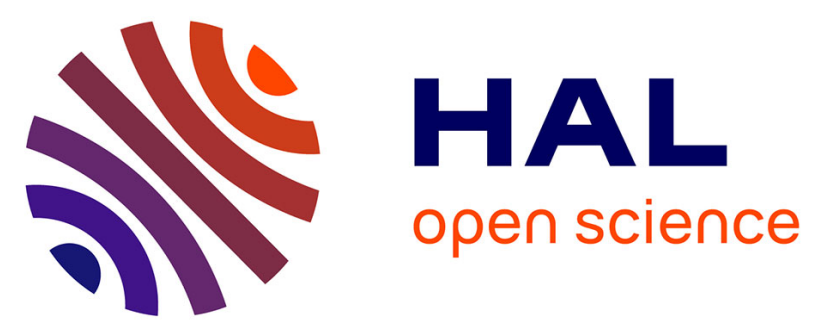

\title{
When are powerful learning environments effective? The role of learner activities and of students' conceptions of educational technology
}

Peter Gerjets, Friedrich Hesse

\section{- To cite this version:}

Peter Gerjets, Friedrich Hesse. When are powerful learning environments effective? The role of learner activities and of students' conceptions of educational technology. International Journal of Educational Research, 2004, 41(6), pp.445-465. 10.1016/j.ijer.2005.08.011 . hal-00197416

HAL Id: hal-00197416 https://telearn.archives-ouvertes.fr/hal-00197416

Submitted on 14 Dec 2007

HAL is a multi-disciplinary open access archive for the deposit and dissemination of scientific research documents, whether they are published or not. The documents may come from teaching and research institutions in France or abroad, or from public or private research centers.
L'archive ouverte pluridisciplinaire HAL, est destinée au dépôt et à la diffusion de documents scientifiques de niveau recherche, publiés ou non, émanant des établissements d'enseignement et de recherche français ou étrangers, des laboratoires publics ou privés. 


\title{
When are powerful learning environments effective? The role of learner activities and of students' conceptions of educational technology
}

\author{
Peter H. Gerjets \& Friedrich W. Hesse \\ Knowledge Media Research Center \\ Konrad-Adenauer-Str. 40 \\ D-72072 Tuebingen, Germany \\ [p.gerjets], [f.hesse]@iwm-kmrc.de
}

\section{Introduction}

Our goal in this paper is to provide a theoretical and empirical perspective on how students' conceptions of educational technology affect the effectiveness of technology-based learning environments. In particular, we focus on how students' conceptions influence learner activities in a given learning environment and thereby moderate the relationship between attributes of the environment and the resulting outcomes.

The term powerful learning environment is often characterized teleologically to denote environments that aim at achieving the development of complex skills, deep conceptual understanding, and metacognitive skills such as self-regulated learning (de Corte, 1990). New information and communication technologies seem to be very apt to implement powerful learning environments (cf. De Corte, 1994; Jonassen, Campbell, \& Davidson, 1994; Salomon \& Almog, 1998). Thus, although the term is not restricted to educational technology applications, we will concentrate on technology-based learning environments that are designed according to a couple of principles that are mainly derived from a constructivist view of learning and thus are assumed to deliver optimal conditions for learning complex skills and for acquiring deep conceptual understanding (cf. de Corte, Greer, \& Verschaffel, 1996).

Unfortunately, there seems to be a gap between the expected effect of powerful learning environments and their factual effectiveness (cf. Lowyck \& Lehtinen, this volume). One reason for this gap might be that - beyond some general prerequisites that need to be fulfilled in order to serve as a powerful learning environment - very little is yet 
known about how to design a powerful learning environment (van Merriënboer \& Paas, 2003). A second and even more fundamental reason might be that attributes of learning environments - contrary to predictions of the specific traditional instructional design perspective - might not have any direct effects on students' learning, especially if we talk about self-regulated learning (cf. Elen \& Lowyck, 1999). As Jonassen, Campbell, and Davidson (1994, p. 36) put it for media-based learning environments: "There is, at best, an indirect link between media and learning" and this link consists in the activities that are enabled by particular media.

In the third section of this paper we will argue that a micro-analysis of learner activities has to be conducted in order to make reliable predictions concerning the effectiveness of learning environments. We hypothesize that powerful learning environments will be effective when first they enable, elicit or afford suitable learner activities and when second learners actually engage in these activities. In our view, designing technology-based learning scenarios according to the constructivist concept of powerful learning environments is by itself not sufficient to ensure that suitable learner activities occur for the following reasons: First, learner activities are determined by a multiplicity of factors besides the attributes of learning environments and second, many learner activities promoted by powerful learning environments may be even more harmful than beneficial for learning. We will substantiate the latter claim with a number of findings on computer-based learning environments that have been obtained by our own research group at the Knowledge Media Research Center in Tuebingen, Germany. We conclude that we need a much more detailed cognitive account of learner activities, their determining conditions, and their effects on learning outcomes than the one that is provided by constructivist theories of learning. Studying learner activities in the context of specific instances of technology-based instruction typically raises two types of questions that cannot be answered by constructivist theories of learning alone:

- We need to know on a rather molecular level of analysis what type of learner activities would be suitable for a given goal of instruction. This issue involves detailed cognitive analyses of learning goals and learning tasks in terms of processes, resources, and cognitive architecture and thus implies reasoning within a cognitive science framework that goes beyond constructivist approaches. 
- Even when the design of a learning environment enables suitable learner activities we have to specify the conditions under which learners really engage in these activities and not in other possible but less effective activities. With regard to this issue a multiplicity of factors besides the attributes of the learning environment may play a role. These factors may include students' knowledge prerequisites, learning styles, learner preferences, motivational orientations, attitudes, epistemological beliefs, and instructional conceptions, whereby the latter term denotes the ideas, concepts, and theories of learners with regard to the learning environment (cf. Lowyck, Elen, \& Clarebout, this volume).

Many of the determining factors of learner activities will be important in powerful learning environments independent of whether these environments are implemented by means of educational technology or not. However, there is one specific type of instructional conceptions that will be of particular importance with regard to learner activities in technology-based learning environments. These are students' ideas, concepts, and theories on educational technology and its use in instruction. However, within the educational community there has been nearly no research conducted up to now that investigates how learners' conceptions, attitudes, knowledge, expectations, and metaphors with regard to educational technology determine specific learner activities in technology-based environments. We will review some relevant findings from related fields like human-computer interaction, attitude research or epistemological beliefs in the fourth section of this paper and outline some implications for future research in this area.

\section{Using educational technology to implement powerful learning environments: A constructivist macro-analysis}

\section{The concept of powerful learning environments}

The concept of powerful learning environments (de Corte, Verschaffel, Entwistle, \& van Merriënboer, 2003) has been introduced from a constructivist perspective on learning in order to refer to learning environments that embody to some degree key ideas of the constructivist approach (de Corte, 1990). Powerful learning 
environments are distinguished from traditional "weak" learning environments and classroom settings that are often based on the assumption that learning is a predominantly individual activity that consists in digesting and memorizing decontextualized and fragmented knowledge and procedural skills that are transmitted by a teacher or by some other instructional media like a textbook (cf. de Corte et al., 1996).

Contrary to that "old" knowledge transmission view of learning, the constructivist concept of powerful learning environments is based on the rather different perspective of "new learning" (Simons, van der Linden, \& Duffy, 2000) that focuses on knowledge construction instead of knowledge transmission, on competencies instead of declarative information, and on social exchange instead of individual learning. According to this view, effective learning can be characterized as:

- constructive and cumulative, i.e., knowledge is generated by the learners themselves during their interaction with environments and on the basis of what they already know.

- authentic and understanding-based, i.e., the most effective learning processes take place in realistic and context-bound environments that allow for meaningful learning and problem solving.

- cooperative, i.e., learning is done together with others in social interaction and collaboration.

- self-controlled and goal-oriented, i.e., learning is seen as an active process that is initiated by the learner according to his own goals and that is motivationally maintained and cognitively regulated by the learner.

The concept of powerful learning environments is used to denote learning environments that enable and support this type of learning activities. Obviously, this concept is in line with several instructional approaches that have recently been developed from a constructivist perspective, e.g., situated learning (Brown, Collins, \& Duguid, 1989), cognitive apprenticeship (Collins, Brown, \& Newman, 1989), problembased learning (Barrows, 1986; Hoffman \& Ritchie, 1997), anchored instruction (Cognition and Technology Group at Vanderbilt, 1990, 1997), or discovery learning (de Jong \& van Joolingen, 1998). 


\section{Using technology to create powerful learning environments}

When considering the role of technology in creating powerful learning environments it has first to be noted that there is no necessary connection between powerful learning environments and advanced learning technologies in terms of computational power, powerful interfaces, and large computer networks. To put it another way: Powerful learning environments as defined before can as well be created without technology, and powerful learning technologies can be used in a way that does not result in powerful learning environments. For instance, the problem-solving training developed by Schoenfeld (1985) is an example of how powerful learning environments - that enable active, constructive, understandingbased, and cooperative learning - can be designed and implemented without relying on technological devices. On the contrary, numerous attempts to use computational power for educational purposes like computer-based drill-and-practice programs or many first generation intelligent tutoring systems are committed to a more traditional conception of learning that focuses on the transmission and memorization of decontextualized knowledge elements and procedural skills.

However, despite this apparent independence between powerful learning environments and these strengths of technology many features of modern information and communication technologies seem to be very apt to support the envisioned processes of constructive, meaningful, collaborative, and active learning (cf. de Corte, 1994; Duffy \& Cunningham, 1996; Jonassen et al., 1994). There are several examples of advanced multimedia technologies that have been emerging recently and that may be suitable to implement powerful learning environments. Instances are web-based hypermedia environments, interactive animations and simulations, interactive hypervideos, collaborative environments for inquiry learning, or virtual realities. These information and communication technologies provide a variety of tools that possess an enormous educational potential in terms of creating powerful learning environments for individual as well as for collaborative learning. From a technological perspective these tools are mainly characterized by three pivotal features that in turn have the potential to support several crucial elements for powerful learning: 
- High computational power allows for different types of interactivity and direct feedback thereby allowing for active, flexible, goal-oriented, and self-controlled learning.

- Connected computers can be used to enable synchronous and asynchronous social interaction and cooperation (e.g., by threaded discussions, chat, email, message boards, collaborative communication platforms) as well as to provide access to large amounts of learning resources (e.g., in hypermedia environments like the World Wide Web).

- High quality visual and auditory interfaces permit to provide realistic and authentic learning materials like (animated) visualizations or virtual realities that might facilitate contextbound and understanding-based learning.

These features fit quite well into the list of three characteristics that van Merriënboer and Paas (2003) postulate to be necessary to make up a powerful learning environment. These characteristics comprise first the use of complex, realistic, and challenging problems that elicit active and constructive processes of knowledge and skill acquisition in learners. Second, learners need to be involved in collaborative work and have to be given ample opportunities for interaction, communication, and cooperation. Third, learners should be encouraged to set their own goals and should be provided with guidance to take more responsibility for their own learning activities and processes. Guidance can be given in different ways (cf. de Corte, 1990) that can be implemented by technological means: Students can observe an expert performing a task (modelling), they can be given hints and feedback on their own performance (coaching), and they can be given direct support (scaffolding) in the early stages of learning with progression from external regulation to self-regulation during the further course of instruction (fading).

Beyond the rather moderate claim that many features of advanced technological tools are congenial to the features of powerful learning environments and thus are appropriate means to implement those environments, a couple of authors go far further in their claims. In contrast to the moderate "amplification" view that using technology as a tool simply allows to amplify what can be done without technology already, the "augmentation" view proposes that technology might augment the possible types of cognitive activity and 
thereby lead to a reorganization and extension of human cognition (Pea, 1985). According to the latter view technological tools might allow to create new ways of constructive, realistic, collaborative, and self-controlled learning experiences and thereby might enable the development of powerful learning environments which can not be implemented without computers. For instance, Landow (1992) argues that hypermedia technology might empower learners to use information in innovative ways and thereby supports multilineal and critical thinking in a way that goes beyond traditional linear text. Furthermore, advanced visualization techniques are said to offer genuinely new ways to represent and thereby to understand phenomena that would not be possible without them. In a similar way, many collaborative learning environments provide facilities for synchronous and asynchronous communication and for sharing documents and other resources that would not have been available without that technology. According to the "augmentation" view instructional technology should not be seen just as a particular way to deliver instructional materials but as a context of learning that influences the whole instructional setting by facilitating activities and cognitive processes of learners unseen in the context of traditional, technology-free instruction (Jonassen et al., 1994). In line with this reasoning, Salomon, Perkins, and Globerson (1991) recommend to analyze learners' cognitions with technology instead of focusing on the effects of technology. From this perspective, technological tools can be seen as "faciltators of constructive learning, rather than the conveyors of instruction" (J onassen et al., 1994, p. 35).

\section{Learner activities and learning outcomes in technology- based learning environments: A cognitive micro-analysis}

\section{Theoretical gaps in the constructivist approach}

The constructivist perspective on learning - that provides the foundation for the concept of powerful learning environments - has without doubt the merit of making a strong case for the claim that learning should focus on realistic competencies and deep conceptual understanding, should take place in a context of complex and authentic learning problems that resemble real life situations, and should involve self-controlled and cooperative learner activities. This 
view is often seen as a counter position to the much narrower and more fragmented view of many cognitive theories that tend to focus on the acquisition of more isolated declarative knowledge elements and individual skills. Nevertheless, from our view it is important to recognize that cognitive theory is a necessary complement to the constructivist concepts and claims that have been introduced in the last section. Many constructivist concepts are rather coarse-grained regulative ideas about how learning situations should look like, however, they often do not have specific connections to cognitive processes or the representations and processing resources they rely on. It has to be criticized that beyond some high-level specifications of necessary ingredients of powerful learning environments and beyond programmatic and teleological characterizations of the type of learner activities that should be fostered by these environments not much is known about their systematic instructional design (van Merriënboer \& Paas, 2003). Dillon (2000, p. 101) criticizes the constructivist perspective on educational technology as well as other "grand views" by means of the same argument when he postulates:

In a nutshell, the theories of the field place emphasis on too many high level claims about the ultimate nature of learning and the human mind, and provide too little analysis of how theory might guide instructional technology design. We need to ground ourselves as a field and to emphasize data over opinion.

In a similar vein, van Merriënboer and Paas (2003) postulate that the concept of powerful learning environments has to be combined with more specific cognitive theories of instructional design. In particular it has to be ensured that powerful learning environments are designed in alignment with the human cognitive architecture and its processing capabilities and limitations. After all, it has to be remembered that all learning processes - including those that are constructive, authentic, cooperative, and self-controlled - have a cognitive basis in that they consist in the generation and manipulation of cognitive structures by means of a resource-limited processing system.

Therefore, we will focus in this section on a cognitive analysis of learner activities in technology-based learning environments. Our first claim will be that the analysis of learner activities has to be much more concise and couched in cognitive terms than it is usually done within the macro-perspective of the constructivist framework. Our 
second claim will be that in order to ensure that the appropriate type of learner activities will be displayed when interacting with a learning environment we need a much more detailed theoretical account of the instructional design that supports these activities and of the learner characteristics that determine which activities learners will choose in a particular learning environment. In technology-based environments students' ideas, concepts, and theories with regard to educational technology and how to use it will be an important factor that influences the learners' activities.

\section{Learner activities: The devil is in the detail}

The basic concept of powerful learning environments seems to be based on two fundamental assumptions that are illustrated in Figure 1. The first assumption is that providing an appropriately designed learning environment will afford constructive, authentic, cooperative, and self-controlled learner activities (arrow 1). The second assumption claims that learner activities which satisfy these specifications of constructivist learning will lead to positive learning outcomes (arrow 2).

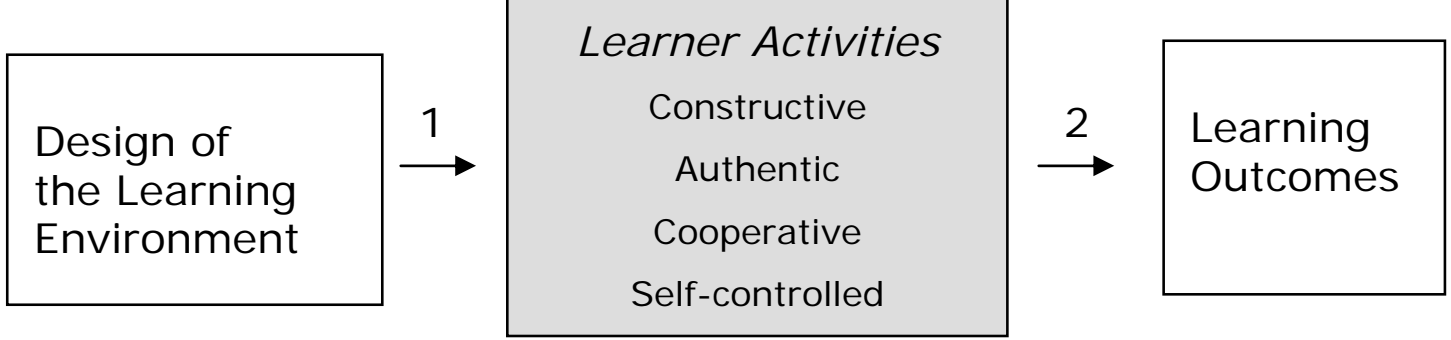

Figure 1: A macro-analysis of learner activities

However, both assumptions of this macro-analysis are rather problematic, and the causal arrows in Figure 1 that refer to these assumptions may be better seen as pointers towards the central theoretical gaps within the constructivist framework which may be responsible for the lack of findings favoring powerful learning environments (cf. Lowyck \& Lehtinen, this volume).

We will first focus on arrow 2 that indicates the "gap between learner activities and learning outcomes". The main issue with regard to this gap is that the description of learner activities in constructivist terms 
is too underspecified to distinguish between learner activities that improve learning outcomes and those that may even hinder learning. In other words, there might be constructive, authentic, cooperative, or self-controlled learning activities that do not result in effective learning, but that even have a negative impact on learning.

The reason for this ambiguity is in our opinion that learner activities that would be described as being equivalent by means of constructivist terms might differ fundamentally in cognitive terms and therefore lead to very different learning outcomes. Our claim is that with regard to learning activities "the devil is in the detail": Thus, a very analytical approach is necessary that defines first which specific learner activities are the ones that are helpful to acquire a particular concept or skill and second which specific conditions in terms of design features of learning environments and instructional tasks are the ones that enable or elicit the execution of these target learner activities. This analytical stance is quite in contrast to the more holistic approach chosen by many constructivist theorists. For instance, Jonassen et al. (1994, p. 35) postulate:

It is difficult or impossible to isolate which components of the learning system, the medium, the attributes, the activities, the learner, or the environment affect learning and in what ways. We delude ourselves when we manipulate attributes of the medium and expect these manipulations to have predictable effect on a process as complex as learning.

We strongly disagree with this type of holistic statement and postulate instead that we need a much more fine-grained analysis of learning environments and learner activities even when - or especially when - the topic is complex skill acquisition. In order to describe and evaluate learner activities at a more fine-grained cognitive level of analysis several additional theoretical perspectives may be necessary to augment the general constructivist approach to learning and instruction. Examples of these theoretical perspectives that we have been using to analyze learning environments, learner activities, and learning outcomes are

- theories of cognitive resource limitations, for instance the cognitive load theory (Sweller, van Merriënboer, \& Paas, 1998) or the cognitive theory of multimedia learning (Mayer, 2001), 
- theories of computational effectiveness with regard to the external representations provided in learning environments (e.g., Ainsworth, 1999; Larkin \& Simon, 1987),

- theories of collaborative knowledge construction (Fischer, 2002), and

- cognitive architectures describing symbolic and subsymbolic knowledge representation and processes of knowledge acquisition, for instance the ACT-R architecture (Anderson \& Lebière, 1998).

We will demonstrate the merits of a more analytic cognitive approach towards the study of learner activities with some examples of technology-based learning environments that were developed and experimentally investigated by our research group at the Knowledge Media Research Center in Tuebingen, Germany. We will use these examples to refute the claim that learning activities will be more or less automatically effective when they are constructive, authentic, cooperative, and self-controlled. To our opinion these characteristics can not be related unequivocally to specific cognitive processes and do therefore not constitute a value per se - they can be useful or harmful for learning depending on the details.

Active and constructive knowledge generation

In order to induce active learner behavior and constructive learning processes it is often advocated from a constructivist perspective to use simulation environments (e.g., de Jong $\&$ van Joolingen, 1998) or interactive dynamic visualizations (e.g., Schnotz, 2002) for learning. In this line of reasoning, Bodemer, Ploetzner, Feuerlein, and Spada (in press) studied different types of static and dynamic visualizations. Their learning environment was made up of symbolic and pictorial representations about how a tire pump works (cf. Mayer, 2001). The representations used consisted of illustrations and corresponding labels that were presented to the students on a computer screen. In two experimental conditions the pictorial and symbolic representations were presented to learners either in spatial separation or in an integrated format with the instruction to mentally integrate the two representations without external activity. In two other experimental conditions learners were provided with an interactive visualization consisting of spatially separated pictorial and symbolic representations on the screen and were asked to relate the 
corresponding components of the representational systems by either dragging and dropping corresponding numbers to both representations (which leaves the representations in spatial separation) or by using drag and drop to integrate the labels within the pictorial representation (which changes the spatial separation of the representations into an integrated format).

These four different experimental conditions can be interpreted in terms of four different sets of learner activities needed to actively construct a coherent mental model of the domain. These sets of activities are "mentally relating separated representations", "mentally relating integrated representations", "externally relating separated representations by assigning corresponding numbers", and "externally relating separated representations by producing an integrated format". Although all four sets consist of active and constructive learning processes, the results of the study show that externally relating representations by using interactive visualizations is more effective with regard to fostering understanding than merely mentally relating representations. Additionally, externally relating separated representations by producing an integrated format is more effective than externally relating separated representations by assigning corresponding numbers. Finally, learning from integrated representations (either provided or produced by the learner) is easier than learning with spatially separated representations. However, just the opposite would have been predicted from a constructivist perspective: From the assumption that constructive learning processes are useful to foster deep conceptual understanding it would have been expected that separated representations provide more opportunities to actively construct relations mentally than integrated representations. Additionally, no difference between the two external drag and drop conditions would have been expected.

In contrast to constructivist accounts, the obtained pattern of results can be rather easily explained by referring to the cognitive load theory (Sweller et al., 1998) and its distinction between beneficial (i.e., germane) and unfavorable (i.e., extraneous) cognitive load imposed onto the learner by the different sets of learner activities and their underlying cognitive processes (for a more detailed explanation of theses concepts compare the model depicted in Figure 3 at the end of this paragraph and its explanation). Basically, the idea is here that learning with multiple, dynamic, and interactive external representations places specific process demands onto learners, such 
as the need to process and relate different representations, to control and evaluate interactions with these representations, and to integrate these representations mentally whereby only some of these process demands are helpful for learning while others are not (cf. Bodemer et al., in press). In sum, this study demonstrates exemplarily that not every constructive activity will improve learning outcomes and that it depends very much on the cognitive details of the learner activities involved in knowledge construction whether a deeper understanding will result or not. Similar findings that rather specific sequences of constructive learner activities will be necessary to profit from technology-based learning environments have also been obtained with regard to other interactive dynamic visualizations like simulation environments for discovery learning (cf. de Jong \& van Joolingen, 1998).

\section{Authentic and realistic learning materials}

From a constructivist perspective the most effective learning processes are assumed to be authentic and understanding-based, i.e, to take place in realistic and context-bound environments that enable meaningful learning and problem solving. Constructivist views such as situated learning or problem-based learning advocate the use of authentic learning environments as a pivotal motivational and cognitive prerequisite for effective learning. High quality visual and auditory interfaces can be used to imitate complex and authentic situations and to deliver realistic learning materials like (animated) visualizations or virtual realities that might facilitate context-bound and understanding-based learning. A well-known example of using dynamic visualizations to foster authentic learning is the Jasper Woodbury Project which is based on interactive videos (Cognition and Technology Group at Vanderbilt, 1997).

Contrary to the constructivist claim that animated visualizations may improve the authenticity of a learning environment and thereby automatically guarantee deep learning the results of Lowe (1999) suggest that learners have trouble focusing on the most relevant parts of an animation and are often distracted by salient, but irrelevant details. In the same line of argumentation, research suggests that only specific ways of using animated visualizations are effective for improving learning outcomes (Pane, Corbett, \& John, 1996). Additionally, research on the augmentation of learning materials with interesting additional information that is, however, 
strictly speaking irrelevant with regard to the pivotal learning contents has demonstrated that attempts to increase learners' interest by such means are accompanied with the risk of performance impairments. This has, for instance, been shown for illustrative pictures and animations that provide a rich context for the contents to be learned. Several accounts have been suggested to explain this seductive details effect (cf. Goetz \& Sadoski, 1995; Harp \& Mayer, 1997, 1998). First, presenting irrelevant additional information may distract learners from processing the pivotal learning contents. Second, irrelevant additional information may trigger inappropriate schemas for encoding the pivotal learning contents. Third, the integration of seductive details in learning materials may lead to increased cognitive demands with regard to working-memory capacity. Thus, from a cognitive perspective it is by no means clear whether authentic or realistic augmentations of symbolic learning materials in terms of animated visualizations will improve or even hinder processes of learning and understanding (cf. Betrancourt \& Tversky, 2000).

For instance, Scheiter, Gerjets, and Catrambone (in press) studied different types of visualizations of worked-out examples in order to find out which kind of visualization may foster the acquisition of problem-solving skills in mathematics. The basic idea behind this research was that visualizations of worked-out examples may first help learners to understand the situation described in the problem statement (i.e., the initial problem state) and thus to correctly represent its meaning in a situation model (Nathan, Kintsch, \& Young, 1992). Second, visualizations of the solution steps used to solve problems may promote an understanding of changes with regard to the initial problem state that is achieved by applying a solution step to a problem. The study of Scheiter et al. (in press) compared three learning environments containing worked-out examples in the domain of probability theory that differed in how realistic the learning materials were. Depending on the experimental condition the workedout examples were either augmented by animated visualizations (high realism), by static pictures (intermediate realism), or by an instruction to mentally imagine the examples' contents (low realism). The results with regard to later problem-solving transfer support the assumption that learners might benefit best from an intermediate realism in the visualization of the cover stories of the worked-out examples: While it could be shown that studying static pictures intensively fostered performance at least on isomorphic problems, 
including dynamics in the external visualizations worsened performance. Thus it seems that the initial idea of using realistic animations to convey knowledge on solution procedures by representing changes in problem states that occur due to applying a specific solution step explicitly was more harming than helpful in that it may even have distracted learners. These results are in line with prior findings of Pane et al. (1996) and Lowe (1999) who found that learners are often overwhelmed by the necessary activities involved in learning from animations (e.g., the number of details they need to identify, select, and to remember in the limited period of time while the information is presented on the changing display). Thus contrary to constructivist intuitions - it might be helpful to provide learners with static pictures or with more abstract (i.e., less realistic) animations in order to reduce the cognitive demands imposed onto them. The broad claim that authentic and realistic learning environments are to be preferred in order to improve learning and understanding seems clearly not to be justified as a general guideline for instructional design. Instead, much more detailed cognitive analyses of the functional aspects of different visualizations for learning will be necessary (e.g., Ainsworth, 1999; Larkin \& Simon, 1987) in order to improve the effectiveness of learning environments that use dynamic animations.

Cooperative learning activities

New information and communication technologies open up new perspectives with respect to establishing innovative collaborative learning environments. For instance, in web-based collaborative inquiry learning environments learners are provided with the opportunity to discuss the evidence for a specific scientific problem, to plan and run experiments to test hypotheses, to communicate and evaluate experimental results, etc. During these activities learners are involved in collaborative work and are given ample opportunities for interaction, communication, and cooperation (e.g., WISE; Slotta \& Linn, 2000). Technologically, these environments use connected computers to foster synchronous and asynchronous social interaction and cooperation as well as access to large amounts of learning resources from the World Wide Web. Inquiry learning environments are intended to improve knowledge acquisition with regard to the scientific content domain addressed as well as with regard to scientific methods and argumentation skills in scientific discourses. However, research has demonstrated that collaborative learning will 
not be effective under all circumstances but that different constraints have to be satisfied in order to ensure the effectiveness of collaborative learning (cf. Slavin, 1996).

For instance, when students interact collaboratively with an inquiry learning environment processes of argumentative knowledge construction can take place. Kollar, Fischer and Hesse (2004) hypothesize that these processes are guided by learners' (often weak) internal scripts on argumentative knowledge construction thereby often resulting in suboptimal learning outcomes. Additional support can be provided by instructional (external) scripts that prescribe the nature and sequence of specific activities like "giving an argument consisting of data, claim, and warrant" and distribute roles among the learning partners. Specific cognitive process theories can be used to design these external scripts. For instance, theories of argumentation can be helpful to describe important structural properties of good arguments (e.g., Toulmin, 1958) as well as the dynamics of how argumentations should develop in discourse in order to exploit the potential of arguments in knowledge building (e.g., Leitão, 2000). From these theories it can be hypothesized that learning outcomes in argumentative knowledge construction will improve when learners engage in specific types of learner activities that correspond to particular roles in the discourse, and when these activities are exhibited in a particular sequence.

Kollar and Fischer (in press) investigated how learners' internal scripts interact with external scripts that are integrated within a webbased inquiry learning environment referring to their effects on knowledge acquisition. They found that most learners were unable to display appropriate patterns of collaborative learning activities in a rather unstructured learning environment where they have to rely fully on their internal scripts for argumentative knowledge construction. Accordingly, highly structured external cooperation scripts could be shown to improve the learning outcomes for many learners. In sum, it is obviously not enough for powerful learning environments to provide learners with opportunities for interaction, communication and cooperation in order to guarantee successful learning. Instead, it is important for effective learning that students engage in specific learner activities and that they exhibit these activities in specific sequences. In order to identify those activities cognitive process theories of collaborative knowledge construction 
have to be used that go beyond a purely constructivist approach (e.g., Fischer, 2002; Fischer, Bruhn, Gräsel \& Mandl, 2002).

Self-controlled learning

Hypermedia systems have often been advocated from a constructivist perspective as suitable learning environments, mainly because they give more control over the learning environments to the students and allow them to become active participants in the learning experience (e.g., Cunningham, Duffy, \& Knuth, 1993; McGuire, 1996). Hypermedia environments are network-like information structures where fragments of information are stored in nodes that are interconnected by electronic hyperlinks. To browse a hypermedia environment means to use a nonlinear link structure in order to get from one piece of information to another instead of following a sequential path that is typically provided by the author of a traditional text. Instead, hypermedia environments are "capable of being explored in different ways, with the different exploration paths producing what are essentially multiple texts for the same topic" (Spiro \& Jehng, 1990, p. 166). Thus, students can select information units and choose the point of time and the pacing and sequence of their presentation according to their own goals and strategies of information integration (Lawless \& Brown, 1997). Accordingly, it has been claimed that hypermedia structures enhance and stimulate selfcontrolled interaction with learning materials in a non-linear fashion, the in-depth exploration of vast amounts of information on demand, and inquiry learning. However, as Gabbard (2000, p. 104) points out, "much of the hypermedia and constructivist literature is made up of broad claims with little, if any, attempt to substantiate these claims". In a review of 30 empirical and quantitative studies on hypermedia learning, Dillon and Gabbard (1998, p. 345) found that "the benefits gained from the use of hypermedia technology in learning scenarios appear to be very limited and not keeping with the generally euphoric reaction to this technology in the professional arena".

From our perspective, one reason for this disappointing state of affairs is that the very general claim that self-controlled learning activities like the exploration of hypermedia environments will more or less automatically lead to effective learning is simply wrong. Again we need a much more detailed cognitive analysis of the relevant processes and resources in order to predict under which conditions hypermedia environments will be beneficial or harmful for learning. 
For instance, we designed an example-based hypertext environment in the domain of probability word problems that allows learners very easily by means of hyperlinks to engage in two types of cognitive processes that are crucial for learning from worked-out examples (Gerjets, Scheiter, \& Tack, 2000). These processes are example comparisons within and among problem categories and example elaborations based on relating examples to the illustrated abstract principles.

In a free-exploration condition learners were allowed to navigate the hypertext environment freely. In a guided-tour condition the materials were presented in a systematic linear sequence without allowing learners to engage in the abovementioned processes of comparing and elaborating examples by means of hyperlinks. The results show that learners in the free-exploration condition did not show better learning outcomes than learners in the guided-tour condition. However, logfile analyses revealed that exactly those navigational patterns that corresponded to profitable cognitive processes of comparing and elaborating examples were associated with better learning and transfer performance (Gerjets, Scheiter, \& Schuh, in press). This apparent contradiction can be simply explained by the fact that only a small number of students actively engaged in profitable patterns of hypermedia exploration when they were allowed to control the learning process on their own. Accordingly, in the words of Lee and Lehman (1993, p. 36), instructional designers should be cautioned not to "assume that all students will be equally willing to explore hypermedia environments to obtain information". Thus, self-controlled learning might not necessarily be a good thing in its own right but depends on the details of how learners use their freedom to control their exploration of a learning environment.

Very similar findings were obtained by Zahn, Barquero and Schwan (in press) who studied the instructional potential of hyperlinked videos that represent a combination of digital video and hypertext. Their study revealed that hypervideos were not in general superior to learning with traditional combinations of text and video. However, they could identify specific patterns of using hyperlinked videos that led to better learning and understanding than the use of text-video combinations without hyperlinks. Again, it was not self-controlled learning that was responsible for improved learning outcomes but specific learner activities that turned out to be beneficial because of the cognitive processes involved in these activities. 


\section{I nfluences on learner activities in instructional environments: A cognitive load model}

As the examples in the previous section should have demonstrated a micro-level analysis of learner activities in terms of the cognitive processes, representations, and resources they rely on is needed in order to be able to predict whether particular learner activities in technology-based learning environments will result in better learning outcomes or not. Contrary to the constructivist concept of powerful learning environments which suggests that the occurrence of constructive, authentic, cooperative, and self-controlled learner activities by itself might suffice to enhance learning and understanding it is our conviction that only at the lower level of cognitive process analyses we can describe which learner activities are beneficial or harmful with regard to the resulting learning outcomes. Different theoretical frameworks might be used to provide such a cognitive analysis (cf. the list of candidate theories in the previous section). One approach that proved fruitful to analyze many of the examples in the previous section is the concept of germane and extraneous cognitive load from cognitive load theory (Sweller et al., 1998) that distinguishes between effective and ineffective learner activities in powerful learning environments. Cognitive load theory focuses on the limited working memory capacity of the human cognitive architecture and on the implications of this resource limitation for the effectiveness of particular learner activities and learning materials.

Gerjets and Scheiter (2003) proposed an extension of that theory that explicitly takes into account the fact that there is no simple oneto-one mapping between instructional environments and learner activities in instructional settings that are characterized by a high level of learner control (cf. Figure 2).

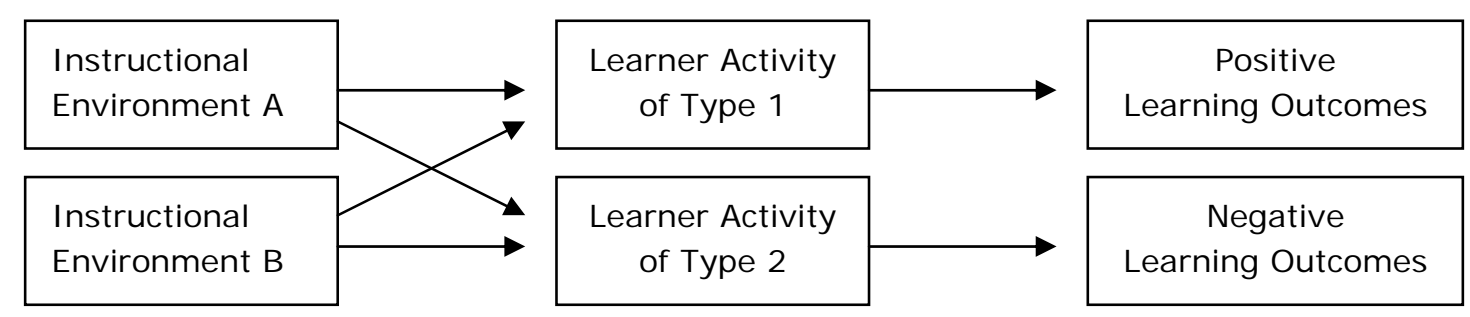

Figure 2: Instructional environments and learner activities in selfcontrolled learning 
For instance, based on the analyses in the previous section we might assume that learner activities of a type 1 are associated with positive learning outcomes while learner activities of a type 2 lead to negative learning outcomes. Nevertheless it may often be the case that learners display activities of type 1 or 2 independent of whether they use a learning environment A or B for learning. According to that view, learner activities are not a stable consequences of specific instructional designs or specific educational devices but depend on several environmental and individual difference variables. Thus, it is of pivotal importance to know under which conditions a particular learning environment will afford favorable learner activities in order to influence learner activities in a positive way. In line with this reasoning Williams (1996) postulates that "a fundamental question that should guide investigators of learner control is: Why do students make the choices they do?".

The model of Gerjets and Scheiter (2003) describes learner activities in terms of goals and strategies as moderators between instructional design and cognitive load. A strategy for performing a task can be defined as "a procedure or set of procedures for achieving a higherlevel goal or task. These procedures do not require conscious awareness to be called a strategy" (Lemaire \& Reder, 1999, p. 365). In this section we will introduce a slightly modified version of this extended cognitive load model in order to systematically analyze the conditions under which learner exhibit beneficial learner activities in self-controlled instructional settings (cf. Figure 3). For a theoretical model of self-regulated learning that is rather close to our own conceptualization see Winne (this volume).

Learner activities are the pivotal unit of analysis in this model and we propose to analyze them in terms of learners' goals and strategies in order to account for the variability with which to-be-learned materials in a given learning environment can be handled. According to this view, a learner who is confronted with a specific learning environment has to decide which goals he or she wants to accomplish during learning and which strategies are to be deployed in order to achieve these goals.

Learner goals will most likely be influenced by affordances of the learning environment (e.g., the tasks assigned in that environment) as well as by instructional conceptions of learners (for instance conceptions with regard to knowledge, learning and educational 
technology, motivational orientations, or study preferences). Both factors, the design of learning environments and the instructional conceptions of learners, will themselves be influenced by conceptions of instructors with regard to learning and teaching. For an overview of how conceptions of instructors may translate into design concepts and systems features see Kettanurak, Ramamurthy and Haseman (2001, p. 548).

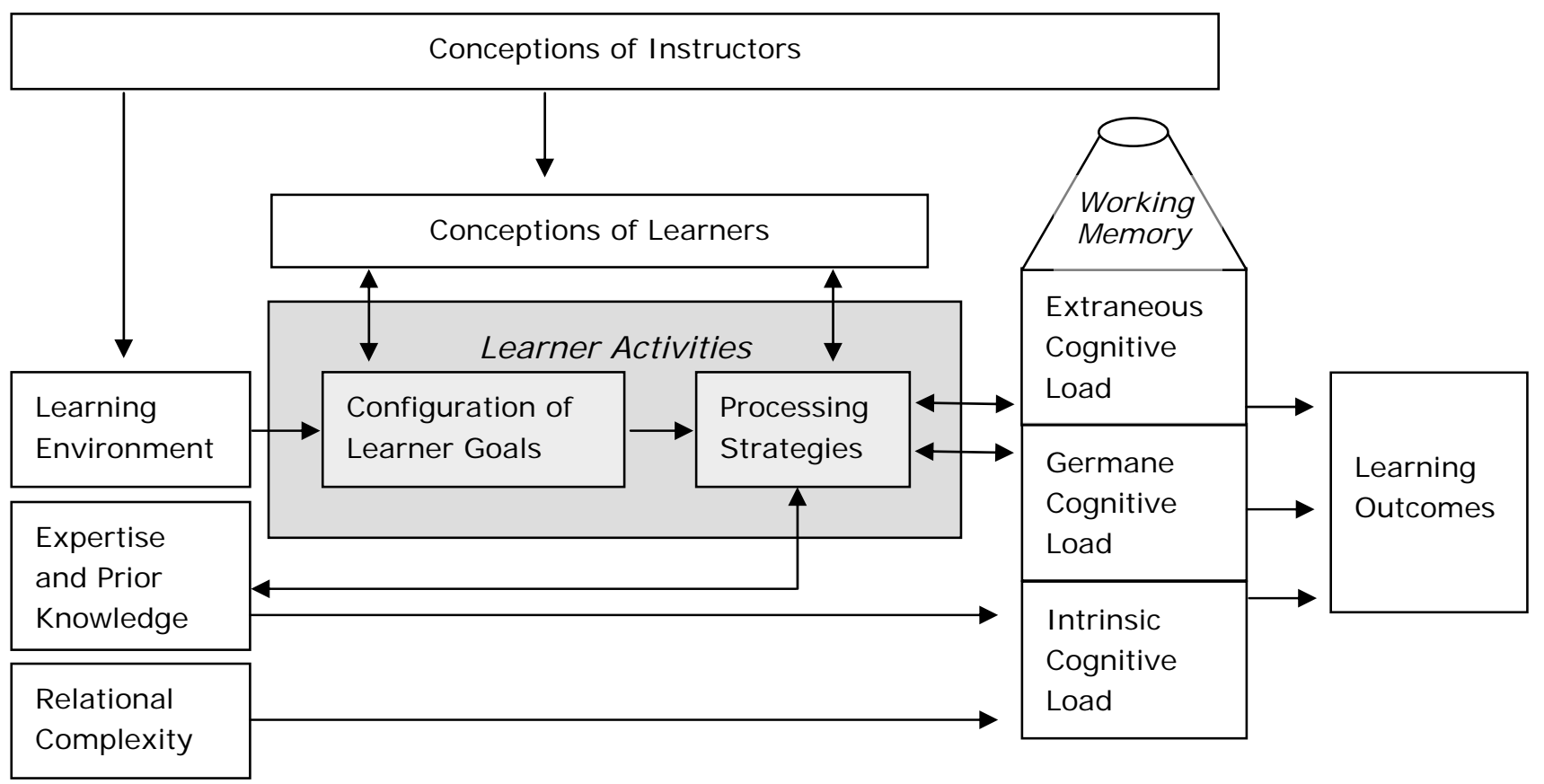

Figure 3: Learner activities, cognitive load, and learning outcomes (figure adapted from Gerjets \& Scheiter, 2003)

Furthermore, learners' processing strategies add variability to the relation between instructional design and learning outcomes. Which processing strategies a learner has at his or her disposal for goal achievement mainly depends on his prior knowledge and expertise. The decision for one of the potential processing strategies will depend on cognitive factors such as the availability of working memory resources as well as on his instructional conceptions. The more freedom the learner has to do what he wants and the more opportunities the learning environment provides for self-control the more important learners conceptions, beliefs, and attitudes with regard to educational technology and learning processes will become. During the course of learning resulting strategic decisions will yield a 
specific sequence of learner activities that is finally responsible for the learning outcomes obtained. Accordingly, the processing strategies deployed by learners are in turn directly responsible for the level of expertise and domain-specific knowledge acquired.

According to cognitive load theory (Sweller et al., 1998) learning outcomes will mainly depend on the pattern of cognitive load imposed onto the learner's working memory by learning materials and learner activities. Working memory is considered the bottleneck of the cognitive architecture with regard to the construction of complex cognitive structures like schemas or mental models. This is because all elements that are to be integrated into a new cognitive structure need to be activated simultaneously in working memory. The theory distinguishes between three types of cognitive load (intrinsic, germane, and extraneous) which are considered to be additive in that, taken together, the total load has to be smaller than the working memory resources available when learning is to occur.

First, the intrinsic relational complexity of the materials to be learned is associated with an intrinsic cognitive load that is independent of the learning environment used for presentation because it is due to the so-called element interactivity of the materials. Accordingly, intrinsic cognitive load will not be altered by manipulating the design of instructional environments but only depends on the content to be learned and on a learner's level of prior knowledge and expertise (i.e., the availability of complex cognitive structures like schemata that allow for the parsimonious representation of learning contents).

As overall cognitive processing resources are limited, the intrinsic cognitive load imposed by a particular learning content leaves a certain amount of cognitive resources unused that could be spent for engaging in additional activities. Accordingly, there is a cognitive load beyond intrinsic cognitive load that is related to the activities elicited by the environment used for learning. Depending on whether these activities contribute to successful learning or not, the theory distinguishes between extraneous (or ineffective) cognitive load and germane (or effective) cognitive load. To differentiate exactly between effective and ineffective cognitive load it is usually necessary to refer back to cognitive process theories that specify important processing components in the acquisition of a particular type of cognitive structure. In our own work, for instance, we combined cognitive load theory with process models on example-based schema 
abstraction (Gerjets, Scheiter, \& Catrambone, 2004) and with a computational ACT-R model of solving mathematical word problems (Gerjets, Scheiter, \& Schorr, in press).

When intrinsic load is high because of complex learning materials or low levels of expertise and when instructional environments elicit or require activities that are not by themselves helpful for learning - and thus result in high levels of extraneous cognitive load - no resources might be left for important learning processes like schema construction or elaborative inferences. This theoretical perspective may be especially fruitful to be applied to technology-based learning environments that allow for a high level of interactivity. For instance, in computer-based learning environments extraneous cognitive load might result from cognitive processes necessary to operate the computer and to interact with the learning environment. Thus, from the perspective of cognitive load theory, designing technology-based instructional environments should mainly aim at reducing unnecessary extraneous cognitive load and at imposing germane cognitive load by forcing learners to invest mental effort in activities that foster the construction of complex cognitive structures. As demonstrated in the previous section this may involve, however, to reduce learners' opportunities for constructive, cooperative, authentic, and self-controlled learning.
Although authentic whole learning tasks are considered the driving force for learning in powerful learning environments, we acknowledge that their complexity in the form of high element interactivity or intrinsic cognitive load in combination with the load caused by the manner in which the information is presented, may hamper learning by the limited processing capacity of working memory.
(Van Merriënboer \& Paas, 2003, p. 14)

Analyzing learners' interactions with technological learning environments at a fine-grained level of learner activities, learner goals, processing strategies, and resulting patterns of cognitive load can be expected to predict learning outcomes much better and to inform the design of powerful learning environments in a more efficient way than the coarse-grained analyses provided by many constructivist theories. 


\section{Learner activities in technology-based environments and their conceptions of educational technology}

According to the analysis given in the previous section it is of vital importance to understand in detail the conditions that lead to the execution of suitable learner activities when designing instructional environments for self-controlled learning. Again, the knowledge on how design features and learner characteristics influence the selection of learner goals and processing strategies has to be rather specific in order to have any impact on improving learning outcomes. Thus, knowing correlations between design features, learner characteristics, and learning outcomes without integrating more specific process assumptions will not be sufficient.

Even worse, simply assuming that providing appropriate opportunities for suitable learner activities will be sufficient to elicit these activities is quite naïve and thus might fail to produce the respective learning outcomes. Nevertheless this attitude is quite common within the constructivist framework (Petraglia, 1998, p. 60):

The model of a learner who is cleansed of inappropriate attitudes and motivations continues to lie at the heart of constructivist education. Such a learner is not merely predisposed to efficiency and logic, but is affectively compliant with the educator's desires. This reflects many constructivists' somewhat sentimental presumption that students are fairly bursting with enthusiasm to learn if only educators would let them.

Contrary to this sentimental view, learners may simply not engage in suitable learning activities even when these activities are enabled by the design of a learning environment. Thus, we have to specify the conditions under which learners really engage in these activities and not in less effective activities. Thereby we have to keep in mind that - besides the attributes of the learning environment - there might be a multiplicity of individual difference variables that play a role, for instance instructional conceptions of the learners that are in the focus of this special issue (cf. Lowyck, Elen, \& Clarebout, this volume). Many of these instructional conceptions will be important in powerful learning environments independent of whether these environments are implemented by means of educational technology or not. However, there is one specific type of instructional conceptions that 
will be of particular importance with regard to learner activities in technology-based learning environments. These are students' ideas, concepts, and theories on educational technology and its use in instruction.

Unfortunately, almost no research has been conducted with regard to this particular type of instructional conceptions within the educational community. In particular, we are not aware of a research program that investigates how instructional conceptions related to educational technology determine specific learner activities in technology-based environments. In the remainder of this paper we will therefore review some relevant findings from neighboring fields like cognitive modeling, epistemological beliefs, attitude research, or humancomputer interaction. We will use these findings to outline some research desiderates that should be addressed by the educational community in the future.

\section{Cognitive modeling of learner activities: Simple mechanisms might guide learners' choice of processing strategies}

The highest level of precision with regard to predicting learner activities in self-controlled instructional settings is probably the construction of a computational cognitive model. Computational cognitive models have proven very useful for the design of intelligent tutoring systems (Anderson, Boyle, Corbett, \& Lewis, 1990) as well as for the analysis of how users navigate hypermedia structures (cf. Pirolli \& Card, 1999). Gerjets, Scheiter, and Schorr (in press) used the ACT-R architecture proposed by Anderson \& Lebière (1998) to model learner activities in a hypertext environment computationally. The focus of this model was on the role of distracting information that is irrelevant with regard to the pivotal learning contents but may result in a more authentic learning environment by providing richer context information. In authentic learning environments learner goals may include transient goals that emerge during the navigation in instructional environments (cf. Hirashima, Hachiya, Kashihara, \& Toyoda, 1997) or goals that are related to prospective tasks (cf. Heise, Gerjets, \& Westermann, 1997; Scheiter, Gerjets, \& Heise, 2000) as well as to personal interests (cf. research on seductive details, Garner, Gillingham, \& White, 1989; Harp \& Mayer, 1998) and that, accordingly, lead to distraction and extraneous cognitive load 
instead of fostering learning. When learning environments are augmented by such seductive details it is crucial to understand the conditions under which learners will use the information provided to engage in task-relevant or task-irrelevant learning activities. When seductive details elicit task-irrelevant learner activities an increased level of extraneous cognitive load will result that might prevent learners from engaging in cognitively demanding processing strategies with regard to the pivotal learning contents.

In three experiments we augmented an example-based hypertext environment in the domain of probability word problems with additional illustrative information. This information was related to the cover stories of the worked-out examples used to explain mathematical problem categories and could be retrieved by hyperlinks embedded in these examples. Beyond manipulating the presence of hyperlinks that allow to retrieve seductive details within the learning environment we also varied the configuration of learner goals experimentally by announcing different tasks to the learners. Subjects without goal competition were only instructed to work on a learning and problem-solving task within the hypertext environment. Subjects in the condition with goal competition were informed at the beginning of the experiment that they - after having finished the learning and problem-solving task - would have to work on a second task within the same hypertext environment. The second task consisted of answering three questions about the cover stories of the worked-out examples used for learning. Subjects were instructed to work on the learning and problem-solving task first and to postpone thinking about the question-answering task.

By means of logfile analyses navigational patterns could be identified that indicated profitable and "deep" cognitive processes of studying worked-out examples. Additionally, logfiles could also be used to reveal that learners became distracted and started to browse irrelevant information or to process worked-examples in a superficial way. Our experiments demonstrated that substantial performance impairments are to be expected due to the mere availability of taskirrelevant information when this information is related to other pending goals of learners. This was true even when seductive details were not actively retrieved by learners. Performance impairments have been particularly severe when learning tasks were rather easy to accomplish. On a theoretical level it could be demonstrated that performance impairments due to the availability of task-irrelevant 
information can be traced back to an increased level of extraneous cognitive load that results in the choice of simpler processing strategies when studying worked-out examples.

Based on the rather complex pattern of findings in these experiments we developed a computational simulation of learners' activities in the hypertext environment that explains distraction effects on performance by taking into account learner goals, possible processing strategies, and patterns of cognitive load (Gerjets, Scheiter, \& Schorr, in press; Schorr, Gerjets, \& Scheiter, 2003). This model proved useful to explain distraction behavior, strategy shifts, and performance impairments obtained experimentally. Despite its explanatory power, the model mainly relied on a small set of very simple mechanism which have been derived from computational cognitive models of elementary control processes in multiple-task performance, namely activation mechanisms and executive control productions. For instance, we assumed that current (and pending) goals of the learner act as sources of activation that guide spreading activation throughout the declarative memory. It is assumed that processing strategies encoded in the procedural memory can be executed when their preconditions in terms of cognitive resources and external information provided are satisfied. Hyperlinks are encoded as sources of external information that can be accessed by clicking. The goal relevance of hyperlinks is assessed by the model in terms of the degree of goal cueing resulting from encoding a hyperlink detected on the screen (cf. Altmann \& Trafton, 2002; Pirolli $\&$ Card, 1999). If hyperlinks cue competing goals executive control productions "fire" to choose one of the competing goals for accomplishment. This mechanism of conflict resolution results in processing demands that decrease the amount of cognitive resources available for processes related to the main task. Accordingly, simpler processing strategies are chosen that result in performance impairments.

In sum, rather simple processing mechanisms and representational assumptions were included in our model of distraction effects in hypermedia learning. These assumptions are on the one hand well justified by their integration within unified theories of the human cognitive architecture (cf. Anderson \& Lebière, 1998; Newell, 1990) and allow on the other hand to model learner activities in terms of goal configurations and processing strategies on a fine grained level of analysis without relying too much on complex learner beliefs and 
conceptions with regard to instruction and educational technology. The lesson that can be learned in the current context from the explanatory success of computational cognitive models of learners' interaction with computer-based environments can be summarized as follows: Some precise ideas (a) what possible concrete strategies and goals are that can be deployed within an environment, (b) how learners procedural representation of the learning environment might look like (i.e., what the learner things about what can be done within the environment), and (c) what the basic mechanisms are that run the cognitive architecture allow very well to predict learners' activities within a given instructional environment. Additionally, these ideas might be rather simple without preventing a computational cognitive model based on them to produce complex patterns of behavior in terms of processing strategies and learning outcomes. Obviously, it is not necessary to express all hypotheses of how learners' conceptions of educational technology influence learner activities by means of computational cognitive models. Nevertheless, the degree of precision and the level of detail that can be achieved by this method can be seen as a regulative idea for developing theoretical accounts of learner activities and their determining conditions in interactive learning environments.

\section{Epistemological beliefs and computer attitudes: How students' belief systems might influence their approach to learning}

\section{Epistemological beliefs}

Over the last decades, several studies that correlate learners' instructional conceptions of knowledge and learning with their strategic approaches to learning have been conducted by researchers interested in epistemological beliefs (cf. Entwistle \& Peterson, this volume). The concept of epistemological beliefs (EBs) refers to students' conceptions about the nature of knowledge, knowing, and learning (cf. Hofer \& Pintrich, 2002). Initially, only one dimension of EBs had been considered ("knowledge is absolute" versus "knowledge is relative"; Perry, 1970). However, in recent years, EBs are increasingly seen as a multidimensional construct that covers different aspects of knowledge and learning (e.g., Duell \& SchommerAikins, 2001; Schommer, 1990). For instance, important beliefs with regard to knowledge concern whether knowledge is stable or changing, whether knowledge consists of isolated bits or interrelated 
concepts, or whether knowledge is received from authorities or generated by personal experience and reflection. I mportant beliefs on learning are related to whether learning occurs gradually or in an all or nothing fashion, whether the ability to learn is fixed or changeable, or weather learning is easy or requires effort. Another recent issue in research on EBs is the context dependency of EBs (Bromme \& Stahl, 2003; Buehl \& Alexander, 2001): It has to be assumed that learners' EBs and their influence on learning are not independent from the knowledge domain, learning task, and learning environment that define the current context of learning. With regard to computer-based instruction Hofer $(2001$, p. 373) postulates that "it is likely that there is an interaction between epistemological beliefs and type of instruction".

Several studies have established that there are substantial correlations between different epistemological-belief dimensions on the one hand and students' learning strategies (e.g., Entwistle, McCune, \& Walker, 2001) and cognitive processes during learning on the other hand (e.g., Kardash \& Howell, 2000; Ryan, 1984). Furthermore, EBs have been demonstrated to influence the standards and goals of learners that determine the processing strategies they will engage in during learning (Schommer, Crouse, \& Rhodes, 1992). According to Aleven, Stahl, Schworm, Fischer, and Wallace (2003, p. 305) "empirical evidence exists of mutual influences between epistemological beliefs and learning processes in traditional as well as technology-based learning environments". Thus, EBs seem to be a good candidate for the type of learner conceptions that influence the activities of learners as illustrated in the model in Figure 3 (for a similar model see Hofer, 2001). In most of the studies that establish this influence subscales of epistemological belief questionnaires are correlated with inventories of study strategies (e.g., the Approaches and Study Skills Inventory for Students ASSIST, Entwistle, 1998; Entwistle \& Peterson, this volume).

To our opinion the research framework used to investigate EBs may well be extended beyond its classical scope to investigate more specific aspects of students' conceptions of educational technology and their impact on learner activities in technology-based learning environments. However, this extension presupposes an augmentation of the research framework with regard to two issues - refining the available belief questionnaires and refining the measurement of learner activities. 
Refining the available belief questionnaires. First, research on EBs has to be explicitly related to technology-based learning. According to Bromme and Stahl (2003, p. 29) "most of the results on the relation between learning an EBs have been established in face-to-face learning scenarios in schools and universities. Up to now only very few studies exist on the effects of EBs during learning with new technologies". However, as technology-based learning environments provide a specific context for learning it may well be that general, domain and context-independent inventories are not very well suited to measure the beliefs that are relevant within a particular learning environment. For instance, Maouri, Jacobson, and Spiro (1997) found inconsistencies between learners' EBs measured by such a general questionnaire and their actual learning activities while studying within a hypertext environment. Accordingly, specific measurement instruments have to be developed that allow students to report their beliefs with regard to features of knowledge (e.g., believability, accuracy, complexity) that is represented by different types of digital media. Additionally, items that allow to investigate beliefs with regard to properties of learning processes in technology-based environments are needed (e.g., how much effort these learning processes require, how effective they are, what kind of knowledge they result in). To our knowledge, no such measurements instruments are available up to now (cf. Duell \& Schommer-Aikins, 2001). Thus, the development of instruments that are more suited to measure EBs in the context of elearning should be part of the research agenda of the educational technology community.

Refining the measurement of learner activities. In the light of our aforementioned analysis of the often subtle relation between learner activities and learning outcomes in technology-based learning environments the measures of students' learning strategies or approaches to learning that are typically used within the EBs research community seem to apply a rather coarse-grained level of analysis. From our perspective it is a research desiderate to define profitable strategies of exploring and utilizing technology-based learning environments on a much more detailed level of description. An example of this research strategy is to calculate correlations between different learning outcomes on the one hand and strategy measures derived from logfile analyses or verbal protocols on the other hand (e.g. Chi, Bassok, Lewis, Reimann, \& Glaser, 1989; Scheiter et al., 2000). In a second step it has to be investigated how students' EBs with regard to properties of knowledge and learning processes in 
technology-based environments influence learner activities of specific relevance within these environments. For instance, based on the finding that on-demand help systems like context-specific hints, hyperlinked background materials, or on-line glossaries proved to be very helpful to students when used appropriately (cf. Aleven et al., 2003), Bromme and Stahl (2003) investigated how EBs influenced help-seeking behavior within an interactive learning environment in biology. They concluded that EBs are an important factor for students' activities that strongly influences learning within interactive learning environments. However, empirical studies that analyze the relationship between learners' epistemological conceptions and specific features of their activities within interactive learning environments at this level of precision are quite rare and should be the target of future work in educational technology.

\section{Computer attitudes}

Beyond the belief variables considered in the previous section a second relevant aspect of learners' conceptions of technology might be learners' attitudes towards computer use in education. Attitudes can be considered as theoretical constructs that relate stimuli to behavior and thus allow for a parsimonious prediction of behavior. According to the well-known theory of reasoned action (Fishbein \& Ajzen, 1975) attitudes are evaluations of attitude objects that may guide to the actions towards these objects. The theory of reasoned action postulates that attitudes guide behavior by their influence on intentions, i.e. decisions to act in a particular way. Accordingly, computer attitudes can be expected to influence learners' activities in interactive learning environments in terms of the goals and processing strategies they will engage in when confronted with a particular learning environment.

During the last decades several questionnaires have been developed to measure computer attitudes (for an overview see Garcia, 2001; LaLomia \& Sidowski, 1991). However, many of these questionnaires are not very differentiated in that they only measure a general positive or negative evaluation of computers. A typical example is the Computer Attitude Scale (CAS, Nickell \& Pinto, 1986) that contains 20 items each expressing either a positive or negative attitude towards computers in general (e.g., computers make me uncomfortable, may 
be harmful, are difficult to understand versus computers make life easier and faster, eliminate a lot of tedious work, enhance our standard of living). Moreover, it has frequently been remarked in the educational technology literature that the measurement of computer attitudes is often done poorly because attitude variables are not clearly defined, instruments are not developed well and attitude measurement has tended to be of only peripheral importance to researchers (Simonson \& Maushak, 1996).

With regard to the purpose of predicting specific aspects of learners' activities in interactive environments, however, it will clearly be necessary to measure more specific and well-defined attitude variables. Unfortunately, there are only very few measurement instruments that directly aim to cover attitudes towards different aspects of computer-based instruction. One of the few exceptions is the questionnaire developed by Garcia (2001) that distinguishes eight different dimensions of attitudes towards multimedia-based instruction, namely (a) students' perception of how pleasant the interaction with the computer-based instructional material is, (b) students' attitudes towards learner control, (c) their involvement in multimedia activity, (d) their view on individualized instruction, (e) their attitudes towards self-paced instruction, ( $f$ ) their perception of the environment's user-friendliness, $(g)$ their level of anxiety when working with multimedia, and (h) students' general experience with the instructional material.

Although some of these scales seem to be quite suitable as predictors of how students might use different features of interactive learning environments there is a lack of empirical research on this topic. Rather, most work on computer attitudes has used attitude variables as dependent and not as independent variables. In other words, most studies investigated how ways of designing computer-based learning environments and respective usage patterns might influence computer attitudes and not how computer attitudes might influence usage patterns. Thus, in most research computer-based instruction is mainly seen as a vehicle of attitude change that has to be designed to optimize attitudinal outcomes (cf. Simonson \& Maushak, 1996). An example of this claim is the research on the relation between computer attitudes and learner control. There are several studies demonstrating that the degree of learner control provided by a learning environment influences learners' attitudes towards this environment (e.g., Morrison, Ross, \& Baldwin, 1992). However, we 
are not aware of studies that investigate how different attitude variables might predict whether learners will make profitable use of instructional environments with increased learner control. Thus, the perspective to see attitudes as independent variables that determine learners' behavior in interactive learning environments is not very prominent. Moreover, in the few cases attitudes' influence on learning has been investigated no attention has been paid to the question of how attitudes might have an impact on learning outcomes. For instance, in the model developed by Kettanurak (2001), a direct link between learners' attitudes and performance is assumed without further specification of the mediating cognitive processes.

A positive exception to the lack of research on attitudes as antecedents of behavior in technology-based learning environment is the Technology Acceptance Model (TAM; Davis, Bagozzi, \& Warshaw, 1989) that has been rather influential in the field of management information systems research. TAM integrates the theory of reasoned action that is based on attitudes (Fishbein \& Ajzen, 1975) with belief variables. According to TAM the perceived usefulness and the perceived ease of use of a technology-based environment will determine the attitudes towards this environment and accordingly the users' behavioral intentions and actual system use. Al-Gahtani and King (1999) report a study showing that computer attitudes in combination with belief variables indeed allowed very well to predict the frequency and sophistication level of computer use. Thus, TAM seems to be a fruitful integration of attitudes and belief variables to predict usage patterns. However, this approach from management information systems has not yet been used in the field of educational technology to study students' activities in interactive learning environments. It might thus be a promising avenue for future research to adapt this model or a similar combination of belief and attitude variables to the specific characteristics of technology-based learning environments in order to investigate the role of students' concepts of technology for the learning activities they engage in.

\section{Expectations of computer users: The role of mental models, metaphors, analogies, and perceived task demands}

Research on human computer interaction $(\mathrm{HCl})$ and user-centered design has investigated extensively how factors like the availability of 
processing strategies, of basic skills, and of cognitive resources as well as the representation of particular technological environments influence the effectiveness of users' activities within these environments. This research has put a strong focus on the analysis of users' expectations concerning what will happen when using a computer application, concerning how they should proceed in using the application, concerning the opportunities the technology provides for them, and concerning how these opportunities should be used efficiently. An important theoretical concept that is often used in $\mathrm{HCl}$ research to describe these expectations of users is the rather general concept of mental models (Gentner \& Stevens, 1983; Hueyching \& Reeves, 1992). Mental models are characterized as cognitive representations of reality that people use to understand specific phenomena. Johnson-Laird (1983, p. 397) proposes mental models as the basic structure of cognition: "It is now plausible to suppose that mental models play a central and unifying role in representing objects, states of affairs, sequences of events, the way the world is, and the social and psychological actions of daily life". Mental models allow users to derive expectations when interacting with computer environments even though these mental models might be incomplete and not very accurate representations of the environment and only provide simplified explanations of complex phenomena. Mental models can be represented by sets of condition-action rules that allow to "mentally run" the model and to derive expectations for particular circumstances.

It can be assumed that mental models of instructional environments will be gradually built up over time during interaction with these environments. Alternatively to building up a new model of a situation, students can use existing models of similar situations that seem to fit and use these models to guide behavior. The latter alternative will often take place when interacting with novel technological tools for which no specific mental models are yet available for the learner. For instance, many learners have strong mental models of how printed textbooks are organized - but not how hypertext environments are organized (McKnight, Dillon, \& Richardson, 1996). As a consequence, they might use a textbook analogy or a textbook metaphor to guide their navigation within a hypertext environment (Hammond, 1993; McAleese, 1989). Other metaphors that are well known for hypertext environments are card metaphors, tree metaphors, space metaphors or house metaphors. It has been demonstrated that users' models of 
hypertext systems influence their information-seeking strategies and the appropriate use of links and tolls (Bromme \& Stahl, 2002).

Although these metaphors or analogies are helpful to provide learners with mental models of hypertext environments it has to be noted that they may also lead to wrong expectations and thus result in navigational problems and suboptimal utilization pattern. For instance, it is evident that hypertext allows to support activities that go far beyond what is possible with books - however learners might not use the respective features if their activities are guided by a book metaphor. Accordingly, learners prefer those tools that mimic the familiar media and avoid unfamiliar tools (Leventhal, Teasley, Instone, Rohlman, \& Farhat, 1993). Although designers are free to introduce innovative user models that go beyond the physical reality known to users and cover these new capabilities of technology-based instructional environments ("be better than reality", Nielsen, 1999, p. 383) one should nevertheless be aware that users may rely on analogies and metaphors more familiar to them. These familiar models can become rather misleading when instructional environments are designed according to an intended model of the designer that is not familiar to the user. Accordingly, the "consideration of existing models is vital in the design of new versions so as to avoid designing against the intended users' views of how the information should be organized" (McKnight, Dillon, \& Richardson, 1996, p. 631). If existing user models are not taken into account, the tension between the intended model of the designer and the actual models of the learners might result in negative transfer. In order to avoid this negative transfer unnecessary tension between the metaphors of the designers and of the users should be reduced. It can even become necessary that the "designer may have to constrain the computer in order to empower the user" (McKnight et al., 1996, p. 631).

This cognitive analysis of learners' mental models and their role for the choice of activities within interactive learning environments should be kept in mind when considering recommendations to design very innovative environments that go far beyond the reality known to users. An example is Nielsen's (1999, p. 383) recommendation: "Instead of impoverished facsimiles of reality, design from a basis of strength and go beyond reality to things that were impossible in the physical world. It is painful to use the Web, so reward users by giving them something new and better that they didn't get before". Giving 
opportunities to users is simply not enough if one does not consider how users represent the environment and whether their representation will allow them to take the opportunities provided by the designer. However, computers are very powerful media for information presentation that can reorganize cognitive activities and thereby really go beyond facsimiles of reality. Using this potential may imply to change many conceptions and metaphors of learners in the long run in order to produce learner activities that transcend the physical reality - however this may impose additional load and may therefore only be suitable for expert users with sufficient computer experience. In order to keep this additional cognitive load due to unfamiliar user models as low as possible it will be very important to standardize many design aspects so that users do not need a new mental model for each new interactive environment in order to derive appropriate expectations (cf. Nielsen, 1999).

A classical example on how user expectations with regard to technology might influence learners' processing strategies and thereby learning outcomes is the study of Salomon (1984) that investigates why American children and Israeli children differ in their effectiveness of learning from TV. According to Salomon's AIME model deep and elaborative processing of learning materials will not automatically emerge but depends on the amount of invested mental effort (AIME) that is in turn determined by learners' expectancies and skills with regard to the instructional medium. According to Salomon the two most important predictors of AIME are the perceived task demands, i.e., learners' perception of how much effort is required for learning with a particular instructional environment, and the perceived self-efficacy, i.e. learners' perception with regard to their own competence to master a particular learning task. Salomon found that Israeli children took the TV medium more seriously with regard to the perceived task demands and therefore engaged in deeper processing of the information presented while American children processed the information in a global, shallow, and holistic way because they perceived television primarily as a medium for entertainment and relaxation.

In accordance with Salomon's model it can be expected that several multimedia technologies that are quite similar to TV or movie (like hypervideos, animations or virtual realities) may lead learners to the erroneous expectation that no effortful deep processing is necessary (low perceived task demands) because these technologies can be 
rather passively used for information, entertainment or relaxation. Accordingly, low levels of invested mental effort and unsatisfactory learning outcomes may result from users' analogies between interactive learning environments and TV or movie (cf. Zahn, Barquero, \& Schwan, in press). This may be particularly true for learning environments that can on the one hand be considered to provide a very authentic context for learning, e.g. virtual realities, but on the other hand suggest to learners that very low levels of effort investment are necessary to interact with the environment. Furthermore, for many learners using computer-based learning environments may result in a low level of perceived self-efficacy because many learners suffer from lack of experience and skill with regard to handling computers and interactive computer applications (or at least believe that this is the case). Again, low levels of invested mental effort may result according to Salomon's model.

To sum up, research on human computer interaction and usercentered design has yielded numerous results on users' activities in interactive environments and how these activities are guided by users' expectations, mental models, analogies, and metaphors. It could be shown in this research that expectations and models of users determine their appropriate use of available tools as well as their degree of effort expenditure. Additionally, many theoretical conceptions in the field of $\mathrm{HCl}$ and user-centered design are already developed to a degree of precision that allows to formalize them within computational cognitive models that have been advocated at the beginning of this paragraph as optimal level of analysis to predict learners' activities in interactive learning environments. However, as Dillon has repeatedly postulated $\mathrm{HCl}$ research has not found very much resonance in the educational technology community up to now. From our perspective, it is thus an urgent matter for the future research agenda of educational technologist to take the already existing literature on human computer interaction and user-centered design much more into account (Dillon, 2000, p. 99):

This literature is not largely the work of instructional technologists, but its relevance to their goals is undeniable. Too often it seems, learning technologies are designed without any proper addressing the factors that are important to usable and useful design and implementation. Some times these technologies are even designed in contradiction to such factors. 


\section{Summary}

Our goal in this paper was to outline a theoretical and empirical perspective on how learners' conceptions of educational technology might influence learner activities and thereby determine the effectiveness of powerful learning environments. Starting with an introduction to the concept of powerful learning environments as a concept that is mainly derived from a constructivist view of learning we outlined how recent developments in information and communication technologies might be used to implement powerful learning environments technologically. In the next step we referred to several findings obtained by our research group at the Knowledge Media Research Center in Tuebingen, Germany to argue that the effectiveness of computer-based learning environments will largely depend on very detailed aspects of learners' activities within these environments. As a result, a fine-grained cognitive analysis of learner activities and processing strategies has to be conducted to augment the constructivist framework for designing powerful learning environments. In order to design these environments so that they elicit favorable learner activities, it is necessary to analyze the conditions that determine learners' goals and their choices of processing strategies. The focus of this paper is on how learners' instructional conceptions with regard to educational technology and its use in instruction might influence the selection and execution of suitable learner activities. Unfortunately, there has been conducted nearly no research with regard to this particular type of instructional conceptions within the educational community. Therefore, we reviewed several relevant findings from neighboring fields like cognitive modeling, epistemological beliefs, attitude research, or human computer interaction and user-centered design. We used this review first to demonstrate that there are numerous findings on users' models and expectations with regard to computer-based environments outside the educational technology community that deserve much more resonance in this community than they currently receive. Second, we outlined some implications for future research in educational technology and pointed at some fruitful future directions that might help to further develop this scientific area.

\section{Author note}

We thank Susanne Frings, Stephanie Linek, Katharina Scheiter, and Julia Schuh for helpful comments on earlier versions of this paper. 
Correspondence concerning this article should be addressed to Peter Gerjets, Knowledge Media Research Center, Konrad-AdenauerStrasse 40, 72072 Tuebingen, Germany. Electronic mail may be sent to p.gerjets@iwm-kmrc.de.

\section{References}

Ainsworth, S. (1999). A functional taxonomy of multiple representations. Computers and Education, 33, 131-152.

Aleven, V., Stahl, E., Schworm, S., Fischer, F., \& Wallace, R. (2003). Help seeking and help design in interactive learning environments. Review of Educational Research, 73 (3), 277-320.

Al-Gahtani, S. S., \& King, M. (1999). Attitudes, satisfaction and usage: factors contributing to each in the acceptance of information technology. Behavior \& Information Technology, 18 (4), 277-297.

Altmann, E. M., \& Trafton, J. G. (2002). Memory for goals: An activation based model. Cognitive Science, 26, 39-83.

Anderson, J.R., Boyle, C.F., Corbett, A. \& Lewis, M.W. (1990). Cognitive Modelling and intelligent Tutoring. Artificial Intelligence, 42, 7-49.

Anderson, J. R., \& Lebière, C. (1998). The atomic components of thought. Hillsdale, $\mathrm{NJ}$ : Erlbaum.

Barrows, H. S. (1986). A taxonomy of problem based learning methods. Medical Education, 20, 481-486.

Betrancourt, M., \& Tversky, B. (2000). Effect of computer animation on users' performance: A review. Le Travail Humain, 63, 311329.

Bodemer, D., Ploetzner, R., Feuerlein, I.,\& Spada, H. (in press). The active integration of information during learning with dynamic and interactive visualisations. Learning and Instruction.

Bromme, R., \& Stahl, E. (2002). Writing hypertext and learning: Conceptual and empirical approaches. London: Elsevier. 
Bromme, R., \& Stahl, E. (2003). The impact of epistemological beliefs on e-learning: The case of help seeking. In F. W. Hesse \& Y. Tamura (Eds.), The joint workshop of cognition and learning through media-communication for advanced e-learning (pp. 2935). Berlin: Deutsch-Japanisches Zentrum.

Brown, J. S., Collins, A., \& Duguid, P. (1989). Situated cognition and the culture of learning. Educational Researcher, 18 (1), 32-42.

Buehl, M. M., \& Alexander, P. A. (2001). Beliefs about academic knowledge. Educational Psychology Review, 13 (4), 385-418.

Chi, M. T. H., Bassok, M., Lewis, M., Reimann, P., \& Glaser, R. (1989). Self-explanations: How students study and use examples in learning to solve problems. Cognitive Science, 13, 145-182.

Cognition and Technology Group at Vanderbilt (1990). Anchored instruction and its relationship to situated cognition. Educational Researcher, 19 (6), 2-10.

Cognition and Technology Group at Vanderbilt (1997). The Jasper project: Lessons in curriculum, instruction, assessment, and professional development. Mahwah, NJ : Erlbaum.

Collins, A., Brown, J. S., \& Newman, D. (1989). Cognitive apprenticeship: Teaching the craft of reading, writing, and mathematics. In L. Resnick (Ed.), Knowing, learning, and instruction: Essays in honor of Robert Glaser (pp. 453-494). Hillsdale, NJ: Lawrence Erlbaum.

Cunningham, D. J., Duffy, T. M., \& Knuth, R. A. (1993). The textbook of the future. In C. McKnight, A. Dillon, \& J. Richardson (Eds.), Hypertext. A psychological perspective (pp. 19-49). New York: Ellis Horwood.

Davis, F. D., Bagozzi, R. P., \& Warshaw, P. R. (1989). User acceptance of computer technology: a comparison of two theoretical models, Management Science, 35, 982-1003.

De Corte, E. (1990). Towards powerful learning environments for the acquisition of problem-solving skills. European Journal of Psychology of Education, 5 (1), 5-19. 
De Corte, E. (1994). Toward the integration of computers in powerful learning environments. In S. Vosniadou, E. de Corte, \& H. Mandl (Eds.), Technology-based learning environments: Psychological and educational foundations (pp. 19-25). Berlin: Springer.

De Corte, E., Greer, B., \& Verschaffel, L. (1996). Mathematics teaching and learning. In D. C. Berliner \& R. C. Calfee (Eds.), Handbook of educational psychology (pp. 491-549). New York: Simon \& Schuster Macmillan.

De Corte, E., Verschaffel, L., Entwistle, N. J., \& van Merriënboer, J. (Eds.). (2003). Powerful learning environments: Unravelling basic components and dimensions. Oxford: Elsevier.

De Jong, T., \& van Joolingen, W. R. (1998). Scientific discovery learning with computer simulations of concept domains. Review of Educational Research, 68, 179-202.

Dillon, A. (2000), Designing a better learning environment with the web: problems and prospects, CyberPsychology \& Behavior, 3 (1), 97-101.

Dillon, A. \& Gabbard, R. (1998). Hypermedia as an educational technology: A review of the quantitative research literature on learner comprehension, control, and style. Review of Educational Research, 68 (3), 322-349.

Duell, O. K., \& Schommer-Aikins, M. (2001). Measures of people's beliefs about knowledge and learning. Educational Psychology Review, 13 (4), 419-449.

Duffy, T. M., \& Cunningham, D. J. (1996). Constructivism: Implications for the design and delivery of instruction. In D. H. J onassen (Ed.), Handbook of research for educational communication and technology (170-198). New York: Simon \& Schuster Macmillan.

Elen, J., \& Lowyck, J. (1999). Metacognitive instructional knowledge: Cognitive mediation and instructional design. Journal of Structural Learning \& Intelligent Systems, 13 (3-4), 145-169.

Entwistle, N. J. (1998). Approaches to learning and forms of understanding. In B. Dart \& G. Boulton-Lewis (Eds.), Teaching 
and learning in higher education. Melbourne: Australian Council for Educational Research.

Entwistle, N. J., McCune, V. S., \& Walker, P. (2001). Conceptions, styles, and approaches within higher education: Analytical abstractions and everyday experience. In R. J. Sternberg \& L.-F. Zhang (Eds.), Perspectives on thinking, learning and cognitive styles (pp. 103-136). Mahwah, NJ: Erlbaum.

Entwistle, N. \& Peterson, E. (this volume). Conceptions of learning and knowledge in higher education: Relationships with study behavior and influences of learning environments.

Fischer, F. (2002). Gemeinsame Wissenskonstruktion - theoretische und methodologische Aspekte. Psychologische Rundschau, 53 (3), 119-134.

Fischer, F., Bruhn, J., Gräsel, C., \& Mandl, H. (2002). Fostering collaborative knowledge construction with visualization tools. Learning and Instruction, 12, 213-232.

Fishbein, M., \& Ajzen, I. (1975). Beliefs, attitude, intention, and behaviour. An introduction to theory and research. Boston, MA: Addison-Wesley.

Gabbard, R. (2000). Constructivism, Hypermedia, and the world wide web. CyberPsychology \& Behavior, 3 (1), 103-110.

Garcia, J. F. C. (2001). An instrument to help teachers assess learners' attitudes towards multimedia instruction. Education, 122, 94-102.

Garner, R., Gillingham, M. G., \& White, C. S. (1989). Effects of "seductive details" on macroprocessing and microprocessing in adults and children. Cognititon and Instruction, 6, 41-77.

Gentner, D., \& Stevens, A. (1983). Mental Models. Hillsdale, NJ: Erlbaum.

Gerjets, P., \& Scheiter, K. (2003). Goal configurations and processing strategies as moderators between instructional design and cognitive load: Evidence from hypertext-based instruction. Educational Psychologist, 38, 33-41. 
Gerjets, P., Scheiter, K., \& Catrambone, R. (2004). Designing instructional examples to reduce intrinsic cognitive load: Molar versus modular presentation of solution procedures. Instructional Science, 32, 33-58.

Gerjets, P., Scheiter, K., \& Schorr, T. (in press). Modeling processes of volitional action control in multiple-task performance: How to explain effects of goal competition and task difficulty on processing strategies and performance within AcT-R. Cognitive Science Quarterly.

Gerjets, P., Scheiter, K., \& Schuh, J. (in press). Instruktionale Unterstützung beim Fertigkeitserwerb aus Beispielen in hypertextbasierten Lernumgebungen [Instructional support for skill acquisition from worked-out examples in hypertext-based learning environments]. Zeitschrift für Pädagogische Psychologie.

Gerjets, P., Scheiter, K., \& Tack, W. H. (2000). Resource-adaptive selection of strategies in learning from worked-out examples. In L. R. Gleitman \& A. K. J oshi (Eds.), Proceedings of the 22nd Annual Conference from the Cognitive Science Society (pp. 166171). Mahwah, NJ : Erlbaum.

Goetz, E. T., \& Sadoski, M. (1995). Commentary: The perils of seduction: Distracting details or incomprehensible abstractions. Reading Research Quarterly, 30, 500-511.

Hammond, N. (1993). Learning with hypertext: Problems, principles and prospects. In C. McKnight, A. Dillon, \& J. Richardson (Eds.), Hypertext. A psychological perspective (pp. 51-69). New York: Ellis Horwood.

Harp, S. F., \& Mayer, R. E. (1997). The role of interest in learning from scientific text and illustrations: On the distinction between emotional interest and cognitive interest. Journal of Educational Psychology, 89, 92-102.

Harp, S. W., \& Mayer, R. E. (1998). How seductive details do their damage: A theory of cognitive interest in science learning. J ournal of Educational Psychology, 90, 414-434.

Heise, E., Gerjets, P. \& Westermann, R. (1997). The influence of a waiting intention on action performance: Efficiency impairment 
and volitional protection in tasks of varying difficulty. Acta Psychologica, 97, 167-182.

Hirashima, T., Hachiya, K., Kashihara, A. \& Toyoda, J. (1997). Information filtering using user's context on browsing in hypertext. User Modeling and User-Adapted Interaction, 7, 239256.

Hofer, B. K. (2001). Personal Epistemology Research: Implications for learning and teaching. Educational Psychology Review, 13 (4), 353-383.

Hofer, B. K., \& Pintrich, P. R. (Eds.). (2002). Personal epistemology: The psychology of beliefs about knowledge and knowing. Mahwah, NJ: Erlbaum.

Hoffman, B., \& Ritchie, D. (1997). Using multimedia to overcome the problems with problem based learning. Instructional Science, 25 (2), 97-115.

Hueyching, J. J., \& Reeves, T. C. (1992). Mental models: A research focus for interactive learning systems. Educational Technology, Research and Development, 40 (3), 39-53.

Johnson-Laird, P. (1983). Mental Models. Cambridge, MA: Harvard University Press.

Jonassen, D. H., Campbell, J. P., \& Davidson, M. E. (1994). Learning with media: Restructuring the debate. Educational Technology, Research \& Development, 42 (2), 31-39.

Kardash, C. M., \& Howell, K. L. (2000). Effects of epistemological beliefs and topic-specific beliefs on undergraduates' cognitive and strategic processing of dual-positional text. Journal of Educational Psychology, 92, 524-535.

Kettanurak, V., Ramamurthy, K., Haseman, W. D. (2001). User attitude as a mediator of learning performance improvement in an interactive multimedia environment: An empirical investigation of the degree of interactivity and learning styles. International Journal of Human-Computer Studies, 54, 541-583.

Kollar, I., \& Fischer, F. (in press). Internal and external cooperation scripts in Web-based collaborative inquiry learning - Effects on 
the acquisition of domain-specific an general knowledge. In P. Gerjets, J. Elen, R. Joiner, \& P. Kirschner (Eds.), Instructional design for effective and enjoyable computer- supported learning. Proceedings of the first joint meeting of the EARLI SIG Instructional Design and SIG Learning with Computers [CDROM]. Tuebingen: Knowledge Media Research Center.

Kollar, I., Fischer, F., \& Hesse, F. W. (2004). Computer-supported cooperation scripts - A conceptual analysis. Manuscript submitted for publication.

LaLomia, M. J., \& Sidowski, J. B. (1991). Measurements of computer attitudes: A review. International J ournal of Human-Computer Interaction, 3 (2), 171-197.

Landow, G. (1992). Hypertext: The convergence of contemporary critical theory and technology. Baltimore, MC: John Hopkins University Press.

Larkin, J. H., \& Simon, H. (1987). Why a diagram is (sometimes) worth ten thousand words. Cognitive Science, 11, 65-99.

Lawless, K. A., \& Brown, S. W. (1997). Multimedia learning environments: Issues of learner control and navigation. Instructional Science, 25, 117-131.

Lee, Y. B., \& Lehman, J. D. (1993). Instructional cueing in hypermedia: A study with active and passive learners. Journal of Educational Multimedia and Hypermedia, 2 (1), 25-37.

Leitão, S. (2000). The potential of argument in knowledge building. Human Development, 43, 332-360.

Lemaire, P., \& Reder, L. (1999). What affects strategy selection in arithmetic? The example of parity and five effects on product verification. Memory \& Cognition, 27, 364-382.

Leventhal, L. M., Teasley, B. M., Instone, K., Rohlman, D. S., \& Farhat, J. (1993). Sleuthing in HyperHolmes: An evaluation of using hypertext vs. a book to answer questions. Behaviour \& Information Technology, 12, 149-164. 
Lowe, R. K. (1999). Extracting information from an animation during complex visual learning. European J ournal of Psychology of Education, 14 (2), 225-244.

Lowyck, J., Elen, J., \& Clarebout, G. (this volume). Instructional conceptions and instructional design.

Lowyck, J., \& Lehtinen, E. (this volume). Introduction.

Maouri, C., Jacobson, M. J., \& Spiro, R. (1997). Epistemological beliefs and learning with hypermedia: An investigation. Paper presented at the EARLI Conference, Athen.

Mayer, R. E. (2001). Multimedia learning. Cambridge: Cambridge University Press.

McAleese, R. (1989). Navigation and browsing in hypertext. In R. M. Aleese (Ed.), Hypertext: Theory into practice (pp. 5-38). Oxford: Intellect.

McGuire, E. G. (1996). Knowledge representation and construction in hypermedia and environments. Telematics and Informatics, 14 (4), 251-260.

McKnight, C., Dillon, A., \& Richardson, J. (1996). User-centered design of hypertext/hypermedia for education. In D. H. Jonassen (Ed.), Handbook of research for educational communication and technology (pp. 622-633). New York: Simon \& Schuster Macmillan.

Morrison, G. R., Ross, S. M., \& Baldwin, W. (1992). Learner control of context and instructional support in learning elementary school mathematics. Educational Technology Research and Development, 37 (4), 251-260.

Nathan, M. J., Kintsch, W., \& Young, E. (1992). A theory of algebraword-problem comprehension and its implications for the design of learning environments. Cognition and Instruction, 9, 329-389.

Newell, A. (1990). Unified theories of cognition. Cambridge, MA: Harvard University Press.

Nickell, G. S., \& Pinto, J. N. (1986). The computer attitude scale. Computers in Human Behavior, 2, 301-306. 
Pane, J. F., Corbett, A. T., \& John, B. E. (1996). Assessing dynamics in computer-based instruction. In M. J. Tauber (Ed.), Proceedings of the ACM Conference on Human Factors in Computing Systems (pp. 797-804). Vancouver: ACM.

Pea, R. (1985). Beyond amplification: Using the computer to reorganize mental functioning. Educational Psychologist, 20, 167-182.

Perry, W. G. (1970). Forms of intellectual and ethical development in the college years: a scheme. New York: Holt, Rinehart and Winston.

Petraglia, J. (1998). The real world on a short leash: The (mis)application of constructivism to the design of educational technology. Educational Technology, Research and Development, 46 (3), 53-65.

Pirolli, P., \& Card, S. K. (1999). Information Foraging. Psychological Review, 106 (4), 643-675.

Ryan, M. P. (1984). Monitoring text comprehension: Individual differences in epistemological standards. Journal of Educational Psychology, 76, 249-258.

Salomon, G. (1984). Television is "easy" and print is "tough": The differential investment of mental effort in learning as a function of perceptions and attribution. Journal of Educational Psychology, $76,647-658$

Salomon, G., \& Almog, T. (1998). Educational psychology and technology: A matter of reciprocal relations. Teachers College Record, 100 (1), 222-241.

Salomon, G., Perkins, D. N., \& Globerson, T. (1991). Partners in cognition: Extending human intelligence with intelligent technologies. Educational Researcher, 20 (3), 2-9.

Scheiter, K., Gerjets, P., \& Catrambone, R. (in press). The use of visualizations to foster the acquisition of problem-solving skills in mathematics: Which kind of visualization works? In P. Gerjets, J. Elen, R. J oiner, \& P. Kirschner (Eds.), Instructional design for effective and enjoyable computer-supported learning. Proceedings of the first joint meeting of the EARLI SIG 
Instructional Design and SIG Learning with Computers [CDROM]. Tuebingen: Knowledge Media Research Center.

Scheiter, K., Gerjets, P. \& Heise, E. (2000). Hypertext navigation and conflicting goal intentions: Using log files to study distraction and volitional protection in learning and problem solving. In L. R. Gleitman \& A. K. Joshi (Eds.), Proceedings of the $22^{\text {nd }}$ Annual Conference of the Cognitive Science Society (pp. 441-446). Mahwah, NJ: Erlbaum.

Schnotz, W. (2002). Towards an integrated view of learning from text and visual displays. Educational Psychology Review, 14 (1), 101120.

Schoenfeld, A. H. (1985). Mathematical problem solving. New York: Academic Press.

Schommer, M. (1990). Effects of beliefs about the nature of knowledge on comprehension. Journal of Educational Psychology, 82 (3), 498-504.

Schommer, M., Crouse, A., \& Rhodes, N. (1992). Epistemological beliefs and mathematical text comprehension: Believing it is simple does not make it so. Journal of Educational Psychology, $82,435-443$.

Schorr, T., Gerjets, P. \& Scheiter, K. (2003). Volitional action control in multiple-task performance: Modeling effects of goal competition and task difficulty in ACT-R. In F. Detje, D. Dörner \& H. Schaub (Eds.), Proceedings of the $5^{\text {th }}$ International Conference on Cognitive Modeling (pp. 183-188). Bamberg: Universitäts-Verlag.

Simons, J., van der Linden, J., \& Duffy, T. (Eds.). (2000). New learning. Dordrecht Kluwer.

Simonson, M., \& Maushak, N. (1996). Instructional technology and attitude change. In D. H. Jonassen (Ed.), Handbook of research for educational communication and technology (pp. 984-1016). New York: Simon \& Schuster Macmillan.

Slavin, R. E. (1996). Research on cooperative learning and achievement: What we know, what we need to know. Contemporary Educational Psychology, 21 (1), 43-69. 
Slotta, J. D. \& Linn, M. C. (2000). How do students make sense of Internet resources in the science classroom? In Jacobson, M. J., $\&$ Kozma, R. (Eds.), Learning the sciences of the 21st century. Mahwah, NJ: Lawrence Erlbaum Associates.

Spiro, R. J., \& Jehng, J.-C. (1990). Cognitive flexibility and hypertext: Theory and technology for the nonlinear and multidimensional traversal of complex subject matter. In D. Nix, \& R. J. Spiro (Eds.), Cognition, education, and multimedia (pp. 163-205). Hillsdale, NJ: Erlbaum.

Sweller, J., van Merriënboer, J. G., \& Paas, F. W. C. (1998). Cognitive architecture and instructional design. Educational Psychology Review, 10, 251-296.

Toulmin, S. (1958). The uses of argument. Cambridge, UK: Cambridge University Press.

Van Merriënboer, J. J. G, \& Paas, F. (2003). Powerful learning and the many faces of instructional design: Toward a framework for the design of powerful learning environments. In E. de Corte, L. Verschaffel, N. Entwistle, \& J. J. G. van Merriënboer (Eds.), Powerful learning environments: Unravelling basic components and dimensions (pp. 3-20). Oxford: Elsevier.

Williams, M. D. (1996). Learner-control and instructional technologies. In D. H. Jonassen (Ed.), Handbook of research for educational communication and technology (pp. 957-983). New York: Simon \& Schuster Macmillan.

Winne, P. H. (this volume). Students' calibration of knowledge and learning processes: Implications for designing powerful software learning environments.

Zahn, C., Barquero, B., \& Schwan, S. (in press). Learning with hyperlinked videos - design criteria and efficient strategies for using audiovisual hypermedia. Learning and Instruction. 